\title{
LABORATORY STUDIES OF DENSE BITUMINOUS MIXES-II WITH RECLAIMED ASPHALT MATERIALS
}

\author{
C.Udayshankar ${ }^{1}$, M.Varuna ${ }^{2}$ \\ ${ }^{I}$ M.Tech student, ${ }^{2}$ Assistant professor, Department of civil engineering, R.V. college of Engineering, \\ Bangalore-560059, India \\ c.udayshankars@gmail.com,varun.m07@gmail.com
}

\begin{abstract}
The issue of growing demand on our nation's roadways over that past couple of decades, decreasing budgetary funds, and the need to provide a safe, efficient, and cost effective roadway system has led to a dramatic increase in the need to rehabilitate our existing pavements and the issue of building sustainable road infrastructure in India. With these emergency of the mentioned needs and this are today's burning issue and has become the purpose of the study.

In the present study, the samples of existing bituminous layer materials were collected from NH-48(Devahalli to Hassan) site.The mixtures were designed by Marshall Method as per Asphalt institute (MS-II) at 20\% and 30\% Reclaimed Asphalt Pavement (RAP). RAP material was blended with virgin aggregate such that all specimens tested for the, Dense Bituminous Macadam-II (DBM-II) gradation as per Ministry of Roads, Transport, and Highways (MoRT\&H) and cost analysis were carried out to know the economics. Laboratory results and analysis showed the use of recycled materials showed significant variability in Marshall Stability, and the variability increased with the increase in RAP content. The saving can be realized from utilization of recycled materials as per the methodology, the reduction in the total cost is 19\%, 30\%, comparing with the virgin mixes.
\end{abstract}

Keywords: Reclaimed Asphalt Pavement, Marshall Stability, MS-II, Dense Bituminous Macadam-II

\section{INTRODUCTION}

Road Transport in India accounts for $80 \%$ of passenger movement and $65 \%$ of freight movement. With 3.34 million $\mathrm{km}$ of roads, India has the second largest road network in the world. The current state of our nation's transportation infrastructure is inadequate, and many state and city municipalities do not have the funds to rehabilitate their road networks to improve them to an acceptable level. National Highways Authority of India has prepared plans involving an outlay of Rs 2, 20,000 crores under National Highways Development Program (NHDP) and 10,000 km of expressways at a cost of Rs 1, 00,000 crores are being planned.

The eleventh plan investment in roads and bridges is about Rs $2,78,658$ crores which is about $13.57 \%$ of total outlay. These mega road modernization projects throws up various concerns pertaining to depletion of resources like good soil and aggregates, long lead to get good quality aggregates and increase in fuel consumption etc,. Furthermore, the supply of Bitumen, whose cost keeps on increasing, is dependent on foreign sources, and energy that is needed for processing new materials is becoming costlier every day. Therefore recycling of existing bituminous mixes results in substantial savings through the reuse of aggregates and bitumen. Recycling of asphalt pavements is a technology developed to rehabilitate and/or replace pavement structures suffering from permanent deformation and evident structural damage [3].

Use of the recycled materials in the road construction has been favored over virgin materials in the light of increasing cost of bitumen, scarcity of good quality aggregates and the priority towards preservation of the environment. Considering the material and construction cost alone, it is estimated that using recycled materials, saving ranging from 14 to $34 \%$ can be achieved [2].

\subsection{Objectives}

The main objective of the research is to evaluate the effects of partial replacement of aggregates by RAP on the properties of dense bituminous macadam, Grade-II are

1. To determine the basic engineering properties of the Virgin bitumen and Virgin aggregate and the basic engineering properties of Reclaimed Aggregate and binder after extraction and Recovery.

2. To carry out the blending of RAP and Virgin aggregates for $20 \%$ and $30 \%$ RAP content as per Asphalt Institute (MS-II), according DBM-II gradation as per MoRT $\& \mathrm{H}\left(4^{\text {th }}\right.$ revision $)$. 
3. To carry out the mix design for $20 \%$ and $30 \%$ recycled mixes with virgin mixes as per Asphalt Institute (MSII) and compared with Marshall Properties.

4. To workout the economics of recycling of bituminous pavement materials, comparing with conventional virgin mixes.

\section{EXPERIMENTAL INVESTIGATION}

Representative samples of $200 \mathrm{~kg}$ milled RAP was collected from the NH-48(Devahalli to Hassan stretch) for further investigation. The RAP materials were subjected to solvent (benzene) extraction method by centrifuge extractor and the average bitumen content were found to be 3.2\%.Furtherly, sieve analysis was carried out on the extracted aggregates. It was found that the aggregate lies in the band of specified limits for dense bitumen macadam grade-II as per MoRT\&H,
( $4^{\text {th }}$ revision). The solvent obtained after the extraction taken for distillation to recover the binder for further studies.

\subsection{Evaluation of binder in RAP:}

The binder extracted from RAP was tested for its penetration value and it was found to be $19 \mathrm{~mm}$, which satisfies the minimum criteria of $15 \mathrm{~mm}$.

Furtherly the same evaluated after rejuvenation using virgin $60 / 70$ binder and found to be $48 \mathrm{~mm}$ which also satisfies the minimum criteria as per MoRT\&H, Clause 517.2.6.

\subsection{Virgin and Recycled Aggregate Properties:}

The aggregate properties were measured from the extracted sample (Table-1) and tested for its suitability. Recycled aggregate were found to satisfy the requirements as per MoRT\&H.

Table-1 properties of recycled and virgin aggregates

\begin{tabular}{|l|l|l|l|}
\hline Properties & Virgin & RAP & Permissible Limit \\
\hline Impact value(AIV),\% & 19.62 & 17.12 & 27 max. \\
\hline Crushing value, \% & 22.7 & - & 24 max. \\
\hline Abrasion value, \% & 21.5 & - & 35 max. \\
\hline Specific Gravity,\% & 2.65 & 2.7 & $2.5-3.0$ \\
\hline Combined index,\% & 24.30 & 26 & 30 max. \\
\hline
\end{tabular}

\subsection{Virgin Bitumen Properties:}

For the study, Bitumen 60/70 grade was considered and their properties were tested for its suitability for the study (Table-2).

The bitumen properties were found to satisfy the requirements

Table-2 Properties of Virgin Binder (60/70)

\begin{tabular}{|c|c|c|c|}
\hline Properties & $60 / 70$ & $\begin{array}{c}\text { Permissible } \\
\text { Limit }\end{array}$ & Specification \\
\hline Penetration at $25^{\circ} \mathrm{c}, 5 \mathrm{sec}$ & 64 & $60-70$ & IS -1203:1978 \\
\hline Softening point $(\mathrm{R} \& \mathrm{~B}),{ }^{\circ} \mathrm{C}$ & 49 & $45-55$ & IS -1205:1978 \\
\hline Flash point, ${ }^{\circ} \mathrm{C}$ & 295 & $175 \mathrm{~min}$. & IS -1448:1969 \\
\hline Ductility at $25^{\circ} \mathrm{C}, \mathrm{cm}$ & 82 & 75 min. & IS -1208:1978 \\
\hline Specific gravity & 1.01 & $0.99 \mathrm{~min}$. & IS -1202:1978 \\
\hline Viscosity- $60^{\circ} \mathrm{C}$, poise, $0.3 \mathrm{RPM}$ & 1730 & 1000 min. & ASTM-D 4402 \\
\hline Viscosity- $135^{\circ} \mathrm{C}$, poise, $100 \mathrm{RPM}$ & 3.6 & - & ASTM-D 4402 \\
\hline After RTFO, Loss in weight, \% & 0.40 & 1 max. & - \\
\hline Reduction in Penetration of residue at $25^{\circ} \mathrm{c}, \%$ & 10.93 & $48 \max$. & - \\
\hline Increase in Softening point, ${ }^{\circ} \mathrm{c}$ & 1.27 & - & - \\
\hline
\end{tabular}




\section{MIX DESIGN:}

The mix design was carried out for virgin aggregate as well as for the blended mixture of various ratio of RAP to fresh materials viz., 20:80, and 30:70. The details of RAP gradation and the quantity of fresh aggregates required in accordance with MS-II are summarized in Table-3.

Table-3 Percentage of virgin and RAP aggregates

\begin{tabular}{|c|c|c|c|c|c|c|c|}
\hline \multirow[t]{2}{*}{$\begin{array}{l}\text { Sl. } \\
\text { No }\end{array}$} & \multirow[t]{2}{*}{ IS sieve } & \multirow[t]{2}{*}{$\begin{array}{l}\text { Desired \% } \\
\text { for DBM } \\
\text { mix }\end{array}$} & \multirow[t]{2}{*}{$\begin{array}{l}\text { \% available } \\
\text { in RAP } \\
\text { Material }\end{array}$} & $\begin{array}{l}\% \text { Available of } \\
\text { RAP material }\end{array}$ & $\begin{array}{l}\text { Balance } 80 \% \text { of } \\
\text { Virgin Aggregate }\end{array}$ & $\begin{array}{l}\% \text { Available } \\
\text { of RAP } \\
\text { material }\end{array}$ & $\begin{array}{l}\text { Balance } 70 \% \\
\text { of Virgin } \\
\text { Aggregate }\end{array}$ \\
\hline & & & & \multicolumn{2}{|c|}{$20 \%$} & \multicolumn{2}{|c|}{$30 \%$} \\
\hline 1 & $37.5-26.5$ & 5 & 0 & 0 & 5 & 0 & 5 \\
\hline 2 & 26.5-19 & 12 & 2.9 & 0.58 & 11.42 & 0.87 & 11.13 \\
\hline 3 & $19-13.2$ & 15 & 6.8 & 1.36 & 13.64 & 2.04 & 12.96 \\
\hline 4 & $13.2-4.75$ & 22 & 46.25 & 9.25 & 12.75 & 13.875 & 8.125 \\
\hline 5 & $4.75-2.36$ & 11 & 14.8 & 2.96 & 8.04 & 4.44 & 6.56 \\
\hline 6 & $2.36-0.3$ & 21 & 17.45 & 3.49 & 17.51 & 5.235 & 15.765 \\
\hline 7 & $0.3-0.075$ & 9 & 5.5 & 1.1 & 7.9 & 1.65 & 7.35 \\
\hline 8 & Below 0.075 & 5 & 2.8 & 0.56 & 4.44 & 0.84 & 4.16 \\
\hline & total & & & 19.3 & 80.7 & 28.95 & 71.05 \\
\hline
\end{tabular}

\subsection{Actual Percentage of Virgin Binder:}

The bitumen percentages to be added for preparation of trail mixes are calculated as per MS-II, considering the existing bitumen content in RAP materials. Marshall Properties: Table4 shows the stability and volumetric properties obtained for 20 and $30 \%$ and Virgin mixes.

Table-4 Properties of Recycled and Virgin mixes

\begin{tabular}{|c|c|c|c|c|}
\hline \multirow{2}{*}{ Properties tested } & \multicolumn{2}{|c|}{ Recycled mixes } & \multirow{2}{*}{ Virgin mixes } & \multirow{2}{*}{$\begin{array}{c}\text { Criteria as per } \\
\text { MoRT\&H }\end{array}$} \\
\hline & $20 \%$ & $30 \%$ & & \\
\hline $\mathrm{OBC}, \%$ & 4.37 & 4.1 & 4.63 & ---- \\
\hline Stability, Kn & 23.09 & 25.43 & 21.76 & $9 \mathrm{Kn} \min$ \\
\hline Flow, mm & 3.3 & 3.36 & 3.48 & $2-4$ \\
\hline Air voids, $\%$ & 5 & 3.97 & 4.74 & $3-6$ \\
\hline Unit weight & 2.37 & 2.4 & 3.54 & ----- \\
\hline VMA, $\%$ & 19.73 & 18.18 & 18.14 & $12.5 \mathrm{~min}$ \\
\hline $\mathrm{VFB}, \%$ & 74.59 & 78.1 & 73.84 & $65-75$ \\
\hline
\end{tabular}

The Figure-1 represents the variation in various Marshall

Properties for different percentage of RAP mixes. 


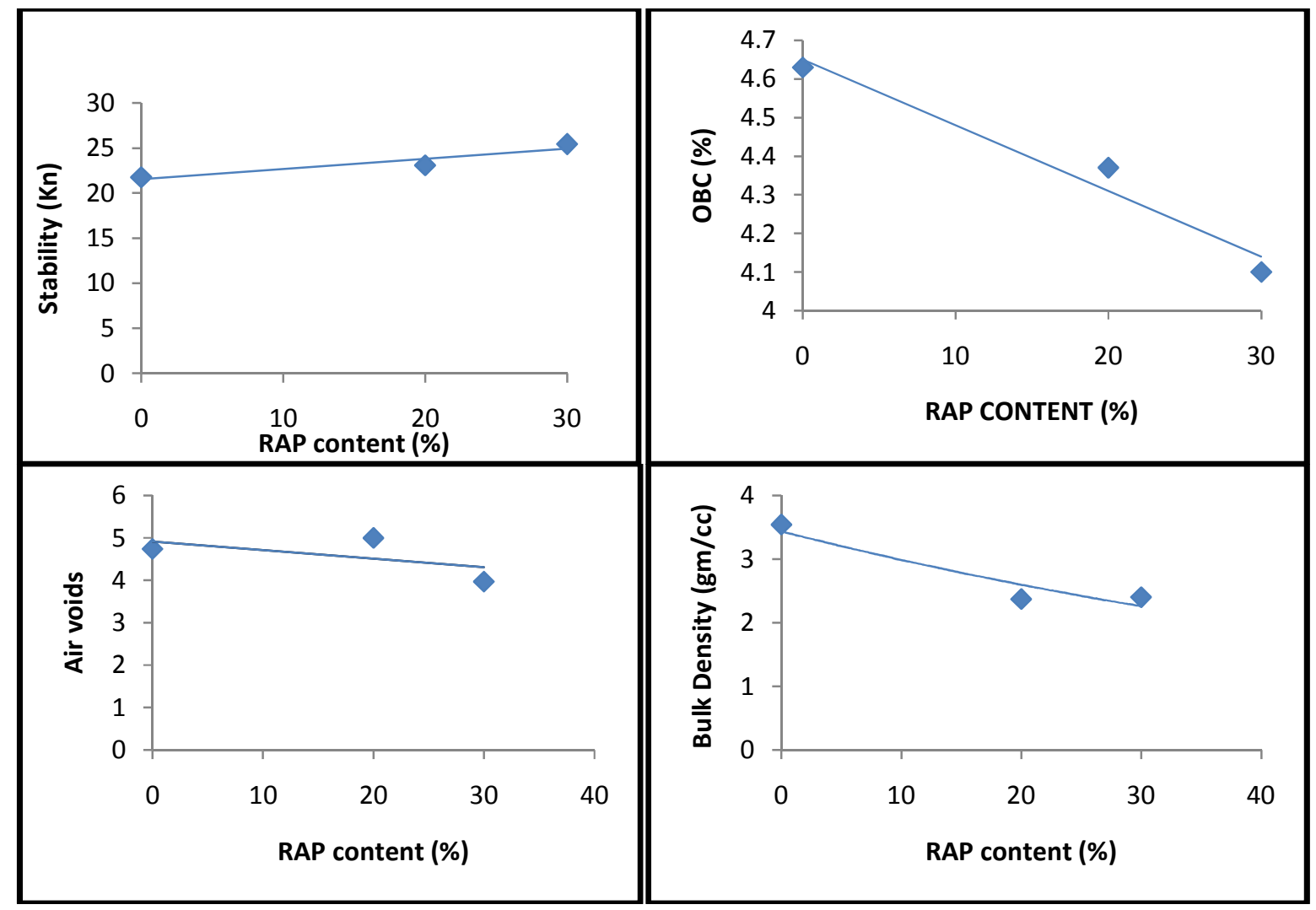

Fig 1 Variation of Marshall Properties

The Figure- 2 shows the variation in the stability for various RAP mixes of 0,20 , and $30 \%$ with respect to bitumen content.

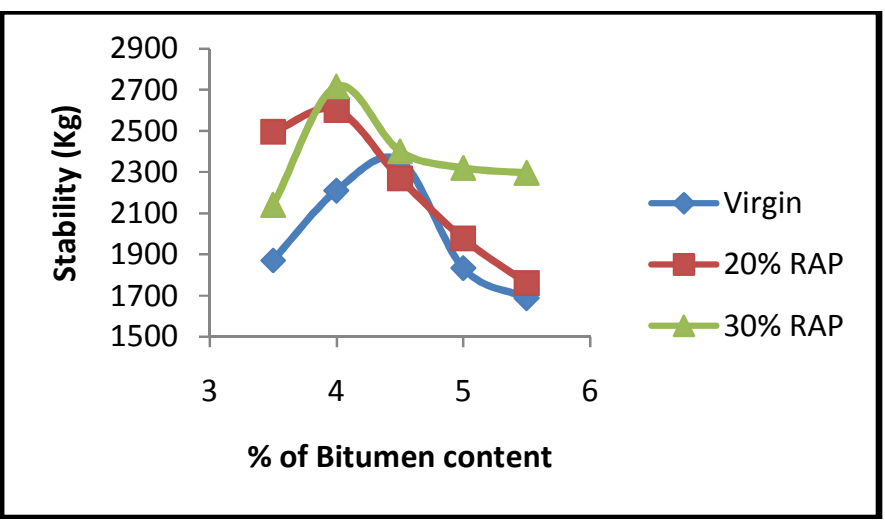

Fig 2 Variation of Stability with respect to bitumen content

\section{ECONOMIC ANALYSIS}

A typical example for one kilometer length for two lane highway, width of $7 \mathrm{~m}$, and depth of $0.1 \mathrm{~m}$ were considered for cost analysis, additionally milling is considered in case of RAP. The costs are calculated based on the schedule of rates of Govt. of Karnataka. The details of economic analysis are shown in Table-5.

Table-5 Economic analysis

\begin{tabular}{|l|c|c|}
\hline Particulars & Total Quantity(cum) & Amount(Rs) \\
\hline Virgin & 733 & $57,43,788$ \\
\hline $20 \%$ RAP & 586 & $46,24,621$ \\
\hline $30 \%$ RAP & 513 & $40,52,593$ \\
\hline
\end{tabular}

\section{CONCLUSIONS}

Based on the experimental result and after analyzing the results, the following may be concluded.

1. DBM-II mixes prepared with RAP materials $20 \%$, $30 \%$ shows higher stability of when compared with the conventional virgin mixes and other Marshall properties are within the specified limits.

2. The saving can be realized from utilization of recycled materials as per the methodology, the reduction in the total cost is $19 \%$, 30\%comparing with the virgin mixes. 


\section{REFERENCES}

[1] Report for Mission Group on Infrastructure Development, Planning Department, Government of Karnataka, September 2010, Pg-1-8.

[2] Kanishak chopra, anjan kumar, Rajib basu mallick and Veeraragavan, "Investigation on laboratory performance of bituminous mixes with reclaimed asphalt pavement materials-a step towards sustainable road infrastructure in India", Journal of Indian road congress, Paper no. 584, December 2012, Pg-339-352.

[3] Valdes, G., Perez-Jimenez, F., Miro, R., Martinez, A., \& Botella, R "Experimental study of recycled asphalt mixtures with high percentages of reclaimed asphalt pavement (RAP)". Construction and Building Materials, 25(3),2011,Pg- 1289 - 1297

[4] K. Aravind, Animesh Das, "Pavement design with central plant hot-mix recycled asphalt mixes", Construction and Building Materials journals - Indian Institute of Technology Kanpur, July 2006, Pg-928-936. 